Article

\title{
Tantalum Arsenide-Based One-Dimensional Photonic Structures
}

\author{
Ilka Kriegel ${ }^{1}$, Michele Guizzardi ${ }^{2}$ and Francesco Scotognella ${ }^{2,3, *}$ \\ 1 Department of Nanochemistry, Istituto Italiano di Tecnologia (IIT), via Morego, 30, 16163 Genova, Italy; \\ ilka.kriegel@iit.it \\ 2 Dipartimento di Fisica, Politecnico di Milano, Piazza Leonardo da Vinci 32, 20133 Milano, Italy; \\ michele.guizzardi@polimi.it \\ 3 Center for Nano Science and Technology@PoliMi, Istituto Italiano di Tecnologia, via Giovanni Pascoli, 70/3, \\ 20133 Milan, Italy \\ * Correspondence: francesco.scotognella@polimi.it
}

Received: 11 July 2018; Accepted: 10 August 2018; Published: 13 August 2018

\begin{abstract}
Weyl semimetals can be described as the three-dimensional analogue of graphene, showing linear dispersion around nodes (Weyl points). Tantalum arsenide is among the most studied Weyl semimetals. It has been demonstrated that TaAs has a very high value of the real part of the complex refractive index in the infrared region. In this work we show one-dimensional photonic crystals alternating $\mathrm{TaAs}$ with $\mathrm{SiO}_{2}$ or $\mathrm{TiO}_{2}$ and a microcavity where a layer of $\mathrm{TaAs}$ is embedded between two $\mathrm{SiO}_{2}-\mathrm{TiO}_{2}$ multilayers.
\end{abstract}

Keywords: photonic crystals; Weyl semimetals; tantalum arsenide; high refractive index materials

\section{Introduction}

Tantalum arsenide is a deeply studied Weyl semimetal [1]. Angle resolved photoemission spectroscopy measurements together with ab initio calculations demonstrated that fermions in TaAs can be described as massless chiral particles with spin 1/2 [2-6]. Recently, Wu et al. [7] have measured a very intense nonlinear optical response of TaAs together with other monopnictide Weyl semimetals, while Weber et al. [8] have studied the ultrafast dynamics of TaAs. Buckeridge et al. [9] have calculated several properties of TaAs, including the dielectric function of the material. Owing to the tetragonal symmetry, an anisotropy of the optical properties arises, with two different dielectric functions when the oscillating electric field is parallel to the $a$ and $b$ axis or parallel to the $c$ axis. In the $c$ direction, at photon energies below $1 \mathrm{eV}$, the imaginary part of the refractive index decreases significantly, while the real part of refractive index has values above 6 . Thus, TaAs can be exploited as a high refractive index material in the infrared region.

For this reason, we want to demonstrate in this work the implementation of tantalum arsenide as a layer in a one-dimensional (1-D) multilayer photonic crystal. One-dimensional photonic crystals are the simplest case of photonic crystals that are materials in which the alternation of high and low refractive indices has a length scale of the light wavelength. In these materials, light is not allowed to propagate for certain photon energies, in correspondence with the so-called photonic band gap [10-13]. One-dimensional multilayer photonic crystals can be fabricated with many fabrication techniques such as sputtering, spin coating, pulsed laser deposition, chemical etching, and molecular beam epitaxy [14-18]. These structures are useful for several applications, for example lasing [15,19], emission control [20-22], and sensing [23-25]. Herein, we show one-dimensional photonic crystals alternating $\mathrm{TaAs}$ with $\mathrm{SiO}_{2}$ or $\mathrm{TiO}_{2}$ and a microcavity where a layer of $\mathrm{TaAs}$ is embedded between two $\mathrm{SiO}_{2}-\mathrm{TiO}_{2}$ multilayers. We show that with very thin layers of TaAs, $16 \mathrm{~nm}$ in the photonic crystals and 
$8 \mathrm{~nm}$ in the microcavity, we can achieve very efficient photonic band gaps and cavity defects, due to the high real part of the refractive index of TaAs in the infrared region.

\section{Methods}

To calculate the optical properties of the different photonic structures studied herein, we have employed the transfer matrix method [26,27]. In our study, the light impinges at normal incidence on a system composed of a glass substrate, the photonic structure, and air.

Briefly, the electric (magnetic) field in air, $E_{0}\left(H_{0}\right)$, is related to the electric (magnetic) field in glass, $E_{m}\left(H_{m}\right)$, through this expression

$$
\left[\begin{array}{l}
E_{0} \\
H_{0}
\end{array}\right]=\prod_{j=1}^{x} M_{j}\left[\begin{array}{c}
E_{m} \\
H_{m}
\end{array}\right]=\left[\begin{array}{ll}
m_{11} & m_{12} \\
m_{21} & m_{22}
\end{array}\right]\left[\begin{array}{c}
E_{m} \\
H_{m}
\end{array}\right]
$$

where $x$ is the number of layers. $M_{j}$ is the characteristic matrix of the layer $j$

$$
M_{j}=\left[\begin{array}{cc}
\cos \left(\phi_{j}\right) & -\frac{i}{p_{j}} \sin \left(\phi_{j}\right) \\
-i p_{j} \sin \left(\phi_{j}\right) & \cos \left(\phi_{j}\right)
\end{array}\right]
$$

$\phi_{j}$ is the phase variation of the light wave passing through the layer, and for normal incidence $\phi_{j}=$ $(2 \pi / \lambda) n_{j} d_{j}$, with $n_{j}$ being the refractive index of the layer, $d_{j}$ is the layer thickness, and $p_{j}=\sqrt{\varepsilon_{j} / \mu_{j}}$ for a transverse electric wave (TE, taking into account that for normal incidence TE and TM show the same behaviour in 1-D photonic crystals).

The transmission coefficient $t$ and the transmission $T$ are

$$
\begin{gathered}
t=\frac{2 p_{s}}{\left(m_{11}+m_{12} p_{0}\right) p_{s}+\left(m_{21}+m_{22} p_{0}\right)} \\
T=\frac{p_{0}}{p_{s}}|t|^{2}
\end{gathered}
$$

We have studied the optical response of a TaAs $/ \mathrm{SiO}_{2}$ photonic crystal, of a $\mathrm{TaAs} / \mathrm{TiO}_{2}$ photonic crystal, and of a $\left(\mathrm{TiO}_{2}-\mathrm{SiO}_{2}\right)_{7}-\left[\mathrm{SiO}_{2}-\mathrm{TaAs}-\mathrm{SiO}_{2}\right]-\left(\mathrm{SiO}_{2}-\mathrm{TiO}_{2}\right)_{7}$ microcavity in the range 0.2-1.1 eV with a step of $2.5 \mathrm{meV}$.

\section{Results and Discussion}

In this work, we studied the optical properties of 1-D photonic crystals made with TaAs alternated with $\mathrm{SiO}_{2}$ or $\mathrm{TiO}_{2}$ and of a microcavity in which TaAs was embedded between two $\mathrm{SiO}_{2}-\mathrm{TiO}_{2}$ Bragg mirrors (seven bilayers), as sketched in Figure 1.

a)

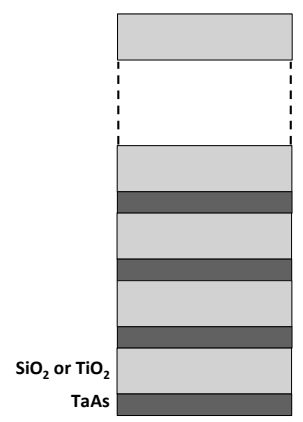

b)

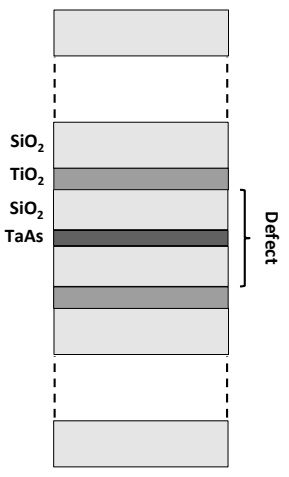

Figure 1. Scheme of (a) a TaAs $/ \mathrm{SiO}_{2}$ (or $\mathrm{TaAs} / \mathrm{TiO}_{2}$ ) photonic crystal and of (b) a $\left(\mathrm{TiO}_{2}-\mathrm{SiO}_{2}\right)_{7}-\left[\mathrm{SiO}_{2}-\mathrm{TaAs}-\mathrm{SiO}_{2}\right]-\left(\mathrm{SiO}_{2}-\mathrm{TiO}_{2}\right)_{7}$ microcavity. 
In Figure 2, we show the light transmission spectrum of a photonic crystal made of seven bilayers of TaAs and $\mathrm{SiO}_{2}$. The thickness of each TaAs layer was $16 \mathrm{~nm}$, while the thickness of each $\mathrm{SiO}_{2}$ layer was $1200 \mathrm{~nm}$. $n$ and $k$ (real part and imaginary part of the refractive index) of TaAs, in the $c$ direction of the crystal, have been taken from Reference [9]. The Sellmeier equation for the dispersion of the refractive index of silica is [28]:

$$
n_{\mathrm{SiO}_{2}}^{2}(\lambda)-1=\frac{0.6961663 \lambda^{2}}{\lambda^{2}-0.0684043^{2}}+\frac{0.4079426 \lambda^{2}}{\lambda^{2}-0.1162414^{2}}+\frac{0.8974794 \lambda^{2}}{\lambda^{2}-9.896161^{2}}
$$

The Sellmeier equation for the dispersion of the refractive index of titania, reliable for thin films in the range $0.2-1.1 \mathrm{eV}$, fits the data by Siefke et al. $[29,30]$ and is

$$
n_{T i \mathrm{O}_{2}}^{2}(\lambda)-1=\frac{4.181 \lambda^{2}}{\lambda^{2}-0.2133^{2}}+\frac{5.068 \lambda^{2}}{\lambda^{2}-14.33^{2}}
$$

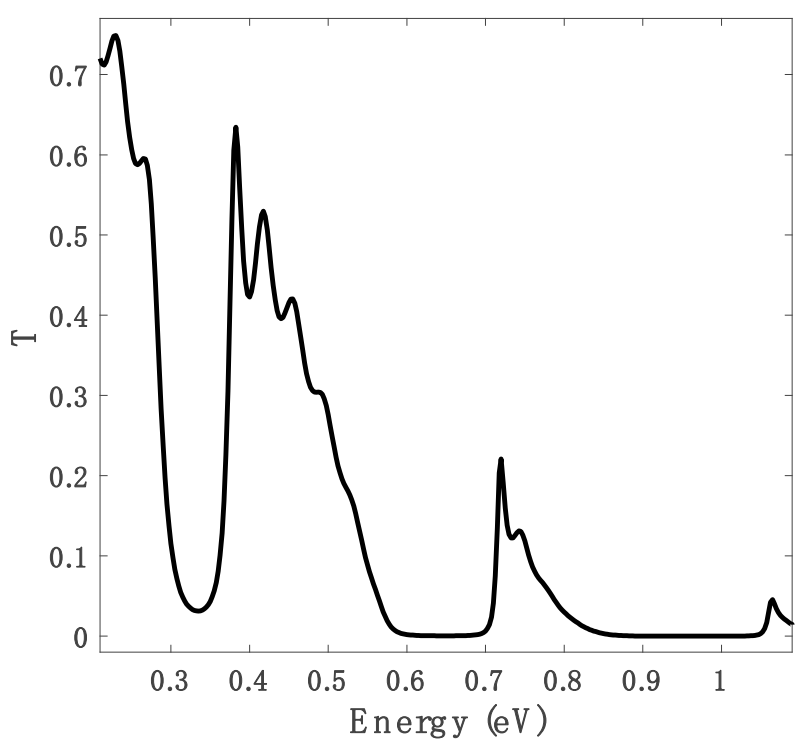

Figure 2. Light transmission spectrum of a 1-D photonic crystal made using seven bilayers of TaAs and $\mathrm{SiO}_{2}$.

For thicknesses of TaAs above $16 \mathrm{~nm}$, the light absorption of the material became very strong because of the high imaginary part of the refractive index.

If we used $\mathrm{TiO}_{2}$ instead of $\mathrm{SiO}_{2}$ to be alternated with TaAs, we observed a photonic band gap in the same spectral position (i.e., $0.35 \mathrm{eV}$ ) with a thickness of the $\mathrm{TiO}_{2}$ layers of $765 \mathrm{~nm}$, resulting in a thinner photonic crystal. In Figure 3, the light transmission spectrum of a photonic crystal made of TaAs and $\mathrm{TiO}_{2}$ is depicted.

In the spectra in Figures 2 and 3, the transmission valley around $0.65 \mathrm{eV}$ was the second order of the photonic band gap of the photonic crystals. For photon energies above $0.8 \mathrm{eV}$, the imaginary part of the TaAs complex refractive index increased significantly, such that the transmission valley at 0.9-1.0 eV was mostly due to TaAs absorption [9].

The photonic band gap was less intense with a $\mathrm{TaAs}-\mathrm{TiO}_{2}$ unit cell (minimum at about 0.1 ) with respect to the one with a $\mathrm{TaAs}-\mathrm{SiO}_{2}$ unit cell (minimum at about 0.03 ) because of the smaller refractive index contrast in the $\mathrm{TaAs}-\mathrm{TiO}_{2}$ case.

In Figure 4, we show the light transmission spectrum of a $\left(\mathrm{TiO}_{2}-\mathrm{SiO}_{2}\right)_{7}-\left[\mathrm{SiO}_{2}-\mathrm{TaAs}_{-}-\mathrm{SiO}_{2}\right]-$ $\left(\mathrm{SiO}_{2}-\mathrm{TiO}_{2}\right)_{7}$ microcavity. The $\mathrm{TiO}_{2}$ layers of the $\left[\mathrm{TiO}_{2}-\mathrm{SiO}_{2}\right]_{7}$ Bragg mirrors were $377.78 \mathrm{~nm}$ thick, while the $\mathrm{SiO}_{2}$ layers were $590.28 \mathrm{~nm}$ thick. In this way, the $\mathrm{TiO}_{2}$ layers and $\mathrm{SiO}_{2}$ layers followed the condition $n_{\mathrm{SiO}_{2}} d_{\mathrm{SiO}_{2}} \cong n_{\mathrm{TiO}_{2}} d_{\mathrm{TiO}_{2}}$. The two $\mathrm{SiO}_{2}$ layers that sandwiched the TaAs layer in the cavity 
defect were $560 \mathrm{~nm}$ thick, while the thickness of the TaAs layer was $8 \mathrm{~nm}$. The microcavity shows in the region $0.31-0.42 \mathrm{eV}$ a photonic band gap with an intense defect peak at $0.376 \mathrm{eV}$. Since $n_{\mathrm{SiO}_{2}} d_{\mathrm{SiO}_{2}} \cong$ $n_{\mathrm{TiO}_{2}} d_{\mathrm{TiO}_{2}}$, the second order of the microcavity photonic band gap was not observed.

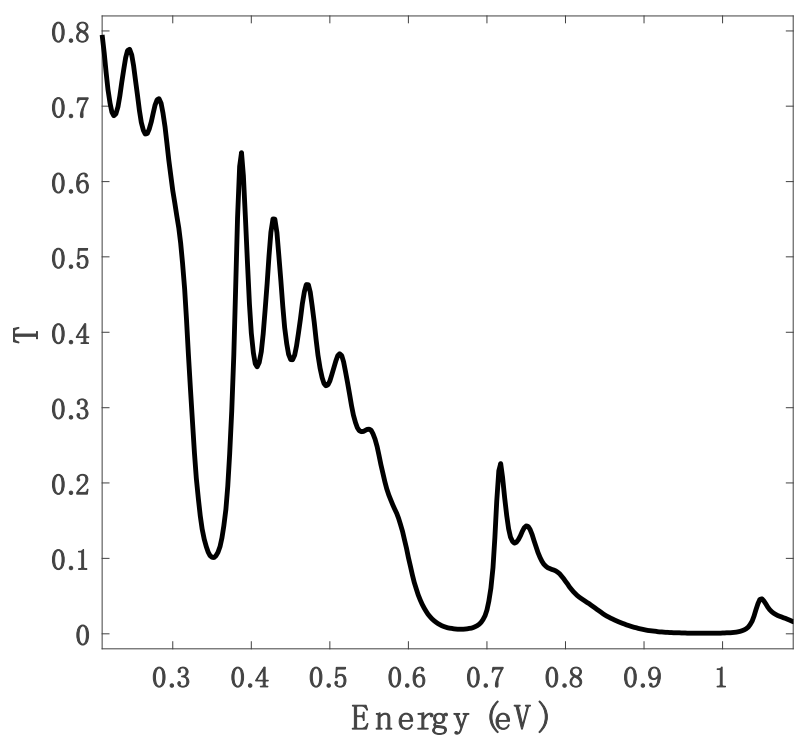

Figure 3. Light transmission spectrum of a 1-D photonic crystal made using seven bilayers of TaAs and $\mathrm{TiO}_{2}$.

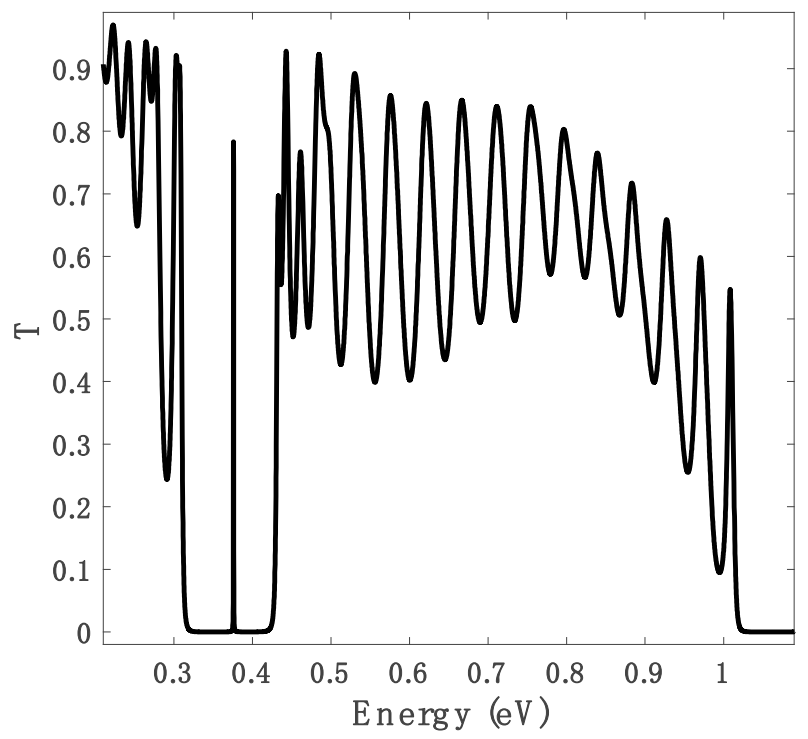

Figure 4. Light transmission spectrum of a $\left(\mathrm{TiO}_{2}-\mathrm{SiO}_{2}\right)_{7}-\left[\mathrm{SiO}_{2}-\mathrm{TaAs}-\mathrm{SiO}_{2}\right]-\left(\mathrm{SiO}_{2}-\mathrm{TiO}_{2}\right)_{7}$ microcavity.

\section{Conclusions}

In this work, we have exploited the high refractive index of tantalum arsenide in the infrared region (in the region $0.2-1.1 \mathrm{eV}$ ), employing the material as a layer in the engineering of a 1-D multilayer photonic crystal and of a 1-D microcavity. We showed one-dimensional photonic crystals alternating $\mathrm{TaAs}$ with $\mathrm{SiO}_{2}$ or $\mathrm{TiO}_{2}$ and a microcavity where a layer of $\mathrm{TaAs}$ was embedded between two $\mathrm{SiO}_{2}-\mathrm{TiO}_{2}$ multilayers. It is worth noting that with thin TaAs layers, 8 to $16 \mathrm{~nm}$ thick, it is possible to build photonic crystals and microcavities in the infrared region with good efficiency. This can be promising for the fabrication of thin filters for this spectral region. 
Author Contributions: I.K. and M.G. contributed with scientific discussions and the writing of paper. F.S. performed the calculations and guided the project.

Funding: This project has received funding from the European Union's Horizon 2020 research and innovation program (MOPTOPus) under the Marie Skłodowska-Curie grant agreement No. [705444], as well as (SONAR) grant agreement No. [734690].

Conflicts of Interest: The authors declare no conflict of interest.

\section{References}

1. Yan, B.; Felser, C. Topological Materials: Weyl Semimetals. Annu. Rev. Condens. Matter Phys. 2017, 8, 337-354. [CrossRef]

2. Xu, S.-Y.; Belopolski, I.; Alidoust, N.; Neupane, M.; Bian, G.; Zhang, C.; Sankar, R.; Chang, G.; Yuan, Z.; Lee, C.-C.; et al. Discovery of a Weyl fermion semimetal and topological Fermi arcs. Science 2015, 349, 613-617. [CrossRef] [PubMed]

3. Yang, L.X.; Liu, Z.K.; Sun, Y.; Peng, H.; Yang, H.F.; Zhang, T.; Zhou, B.; Zhang, Y.; Guo, Y.F.; Rahn, M.; et al. Weyl semimetal phase in the non-centrosymmetric compound TaAs. Nat. Phys. 2015, 11, 728-732. [CrossRef]

4. Lv, B.Q.; Weng, H.M.; Fu, B.B.; Wang, X.P.; Miao, H.; Ma, J.; Richard, P.; Huang, X.C.; Zhao, L.X.; Chen, G.F.; et al. Experimental Discovery of Weyl Semimetal TaAs. Phys. Rev. X 2015, 5. [CrossRef]

5. Lv, B.Q.; Xu, N.; Weng, H.M.; Ma, J.Z.; Richard, P.; Huang, X.C.; Zhao, L.X.; Chen, G.F.; Matt, C.E.; Bisti, F.; et al. Observation of Weyl nodes in TaAs. Nat. Phys. 2015, 11, 724-727. [CrossRef]

6. Lv, B.Q.; Muff, S.; Qian, T.; Song, Z.D.; Nie, S.M.; Xu, N.; Richard, P.; Matt, C.E.; Plumb, N.C.; Zhao, L.X.; et al. Observation of Fermi-Arc Spin Texture in TaAs. Phys. Rev. Lett. 2015, 115. [CrossRef] [PubMed]

7. Wu, L.; Patankar, S.; Morimoto, T.; Nair, N.L.; Thewalt, E.; Little, A.; Analytis, J.G.; Moore, J.E.; Orenstein, J. Giant anisotropic nonlinear optical response in transition metal monopnictide Weyl semimetals. Nat. Phys. 2017, 13, 350-355. [CrossRef]

8. Weber, C.P.; Berggren, B.S.; Masten, M.G.; Ogloza, T.C.; Deckoff-Jones, S.; Madéo, J.; Man, M.K.L.; Dani, K.M.; Zhao, L.; Chen, G.; et al. Similar ultrafast dynamics of several dissimilar Dirac and Weyl semimetals. J. Appl. Phys. 2017, 122, 223102. [CrossRef]

9. Buckeridge, J.; Jevdokimovs, D.; Catlow, C.R.A.; Sokol, A.A. Bulk electronic, elastic, structural, and dielectric properties of the Weyl semimetal TaAs. Phys. Rev. B 2016, 93. [CrossRef]

10. Sakoda, K. Optical Properties of Photonic Crystals; Springer Science \& Business Media: Berlin, Germany, 2004; ISBN 978-3-540-20682-8.

11. Joannopoulos, J.D. Photonic Crystals: Molding the Flow of Light; Princeton University Press: Princeton, NJ, USA, 2008; ISBN 978-0-691-12456-8.

12. Yablonovitch, E. Inhibited Spontaneous Emission in Solid-State Physics and Electronics. Phys. Rev. Lett. 1987, 58, 2059-2062. [CrossRef] [PubMed]

13. John, S. Strong localization of photons in certain disordered dielectric superlattices. Phys. Rev. Lett. 1987, 58, 2486-2489. [CrossRef] [PubMed]

14. Bonifacio, L.D.; Lotsch, B.V.; Puzzo, D.P.; Scotognella, F.; Ozin, G.A. Stacking the Nanochemistry Deck: Structural and Compositional Diversity in One-Dimensional Photonic Crystals. Adv. Mater. 2009, 21, 1641-1646. [CrossRef]

15. Scotognella, F.; Puzzo, D.P.; Zavelani-Rossi, M.; Clark, J.; Sebastian, M.; Ozin, G.A.; Lanzani, G. Two-Photon Poly(phenylenevinylene) DFB Laser. Chem. Mater. 2011, 23, 805-809. [CrossRef]

16. Von Freymann, G.; Kitaev, V.; Lotsch, B.V.; Ozin, G.A. Bottom-up assembly of photonic crystals. Chem. Soc. Rev. 2013, 42, 2528-2554. [CrossRef] [PubMed]

17. Chiasera, A.; Scotognella, F.; Criante, L.; Varas, S.; Valle, G.D.; Ramponi, R.; Ferrari, M. Disorder in Photonic Structures Induced by Random Layer Thickness. Sci. Adv. Mater. 2015, 7, 1207-1212. [CrossRef]

18. Bellingeri, M.; Chiasera, A.; Kriegel, I.; Scotognella, F. Optical properties of periodic, quasi-periodic, and disordered one-dimensional photonic structures. Opt. Mater. 2017, 72, 403-421. [CrossRef]

19. Manfredi, G.; Lova, P.; Di Stasio, F.; Rastogi, P.; Krahne, R.; Comoretto, D. Lasing from dot-in-rod nanocrystals in planar polymer microcavities. RSC Adv. 2018, 8, 13026-13033. [CrossRef]

20. Criante, L.; Scotognella, F. Low-Voltage Tuning in a Nanoparticle/Liquid Crystal Photonic Structure. J. Phys. Chem. C 2012, 116, 21572-21576. [CrossRef] 
21. Lova, P.; Grande, V.; Manfredi, G.; Patrini, M.; Herbst, S.; Würthner, F.; Comoretto, D. All-Polymer Photonic Microcavities Doped with Perylene Bisimide J-Aggregates. Adv. Opt. Mater. 2017, 5, 1700523. [CrossRef]

22. Lova, P.; Cortecchia, D.; Krishnamoorthy, H.N.S.; Giusto, P.; Bastianini, C.; Bruno, A.; Comoretto, D.; Soci, C. Engineering the Emission of Broadband 2D Perovskites by Polymer Distributed Bragg Reflectors. ACS Photonics 2018, 5, 867-874. [CrossRef]

23. Park, C.; Yoon, J.; Thomas, E.L. Enabling nanotechnology with self assembled block copolymer patterns. Polymer 2003, 44, 6725-6760. [CrossRef]

24. Szendrei, K.; Jiménez-Solano, A.; Lozano, G.; Lotsch, B.V.; Míguez, H. Fluorescent Humidity Sensors Based on Photonic Resonators. Adv. Opt. Mater. 2017, 5, 1700663. [CrossRef]

25. Giusto, P.; Lova, P.; Manfredi, G.; Gazzo, S.; Srinivasan, P.; Radice, S.; Comoretto, D. Colorimetric Detection of Perfluorinated Compounds by All-Polymer Photonic Transducers. ACS Omega 2018, 3, 7517-7522. [CrossRef]

26. Born, M.; Wolf, E. Principles of Optics: Electromagnetic Theory of Propagation, Interference and Diffraction of Light; Cambridge University Press: Cambridge, UK, 2000; ISBN 978-0-521-78449-8.

27. Xiao, X.; Wenjun, W.; Shuhong, L.; Wanquan, Z.; Dong, Z.; Qianqian, D.; Xuexi, G.; Bingyuan, Z. Investigation of defect modes with $\mathrm{Al}_{2} \mathrm{O}_{3}$ and $\mathrm{TiO}_{2}$ in one-dimensional photonic crystals. Opt. Int. J. Light Electron Opt. 2016, 127, 135-138. [CrossRef]

28. Malitson, I.H. Interspecimen Comparison of the Refractive Index of Fused Silica. J. Opt. Soc. Am. 1965, 55, 1205-1208. [CrossRef]

29. Siefke, T.; Kroker, S.; Pfeiffer, K.; Puffky, O.; Dietrich, K.; Franta, D.; Ohlídal, I.; Szeghalmi, A.; Kley, E.-B.; Tünnermann, A. Materials Pushing the Application Limits of Wire Grid Polarizers further into the Deep Ultraviolet Spectral Range. Adv. Opt. Mater. 2016, 4, 1780-1786. [CrossRef]

30. Polyanskiy, M.N. Refractive Index Database. Available online: http://refractiveindex.info (accessed on 11 August 2018).

(C) 2018 by the authors. Licensee MDPI, Basel, Switzerland. This article is an open access article distributed under the terms and conditions of the Creative Commons Attribution (CC BY) license (http:/ / creativecommons.org/licenses/by/4.0/). 